\title{
8. Dynamic Chromatin Loops and the Regulation of Gene Expression
}

\author{
Hiroshi Kimura ${ }^{1}$ and Peter R. Cook $^{2}$ \\ ${ }^{1}$ Nuclear Function and Dynamics Unit, HMRO, Graduate School of Medi- \\ cine, Kyoto University, Yoshidakonoe-cho, Sakyo-ku, Kyoto 606-8501, \\ Japan
}

${ }^{2}$ Sir William Dunn School of Pathology, University of Oxford, South Parks Road, Oxford, OX1 3RE, UK

\subsection{Introduction}

Although we have a draft sequence of the human genome, little is known about how the chromatin fiber is packed in three-dimensional (3D) space, or how packing affects function (Jackson 2003). We know packing plays a major role; the rate of transcription of a typical gene can vary over eight orders of magnitude (Ivarie et al. 1983), but deleting local elements like promoters and enhancers reduces expression by less than 5000 -fold in transient transfection assays where the $3 \mathrm{D}$ "context" is missing. Common sense suggests the fiber cannot be packed randomly, but elucidating what any underlying order might be has proved difficult. First, the foldings of the chromatin fiber have dimensions below the resolution $(\sim 200 \mathrm{~nm})$ of the light microscope (LM) and so can only be seen by electron microscopy (EM), but then the fixation required can distort structure. Second, DNA is so long and packed so tightly it breaks and/or aggregates easily on isolation. Third, chromatin is poised in a metastable state so small charge alterations trigger changes in structure and function, and replacing the natural environment with our buffers often promotes aggregation.

Not surprisingly, biochemists minimize aggregation through the use of hypo- and hypertonic buffers, but then different isolates made in different buffers have quite different structures; for example, "matrices" and "scaffolds" contain different sets of DNA sequences associated with dif- 
ferent proteins. Some buffers lead to a stable reduction in contour length of chromatin loops (so new attachments of the chromatin fiber to the underlying structure are generated), others increase it (so some attachments are destroyed; Jackson et al. 1990). Again not surprisingly, observations on the different structures have led to different models including: (i) random packing of the nucleosomal string (Sachs et al. 1995), (ii) helical hierarchies-strings are coiled into solenoids ( $\sim 30 \mathrm{~nm}$ diameter), solenoids into higher-order structures, and so on (Sedat and Manuelidis 1978), (iii) loops $(50-150 \mathrm{kbp})$ attached to the peripheral lamina or internal structures like (iv) skeletons, matrices, scaffolds (e.g., Saitoh and Laemmli 1978), or factories (Cook 1995), and (v) combinations of the above-for example, of helical coils and radial loops (Manuelidis 1990), or helical coils and random folding ( $\mathrm{Li}$ et al. 1998; Strukov et al. 2003). Since there is so little agreement, outsiders often dismiss all the results seen (Cook 1988; Pederson 2000; Belmont 2002).

Here, we concentrate on results obtained using isotonic buffers. We discuss the idea that most large biological structures are intrinsically unstable, persisting only by exchanging subunits with others in their surroundings. We then go on to review evidence for the existence of transient chromatin loops, and propose a general model for the organization of all genomes that involves such loops. Finally, we suggest how ever-changing attachments of the loops to the underlying structure can explain how genes are regulated.

\subsection{Self-Assembly and Self-Organization of Macromolecular Structures}

Macromolecular structures are generated in two fundamentally different ways (Misteli 2001a). Many virus particles "self-assemble" to a fixed plan to attain a true thermodynamic equilibrium; the particles are stable, and survive in the absence of a pool of unincorporated subunits when released from the host. Our houses are similar structures, although we direct their construction; when the builder has finished he removes any unused bricks but the house usually remains standing. But most cellular structures are built differently. Thus, the cytoskeleton lacks a rigid architecture. It is "self-organizing," intrinsically unstable, and persists only by exchanging subunits with others in its surroundings; if those subunits are removed, it collapses and disappears. The structures discussed here fall into the latter category. They are ever-changing, with their shape at any particular moment depending on past and present environments. We cannot make pre- 
cise predictions about the position of any particular molecule or gene within the structure; however, we should eventually be able to predict the probabilities that they will be found in one particular place rather than another. Evidence for the dynamic nature of nuclear structures is reviewed in a number of chapters in this book, and photobleaching studies of the critical components that concern us here-transcription factors and polymerases tagged with green fluorescent protein (GFP) - reveal that they exchange continually with the soluble pool (e.g., Stenoien et al. 2001; Becker et al. 2002; Chen et al. 2002; Dundr et al. 2002; Kimura et al. 2002).

\subsection{Chromatin Loops}

\section{Evidence}

The idea that the chromatin fiber is looped is one of the oldest in cell biology. Images of the lampbrush chromosomes that can be isolated from oocytes are often cited as providing the best evidence for looping. During the first meiotic division, duplicated homologues pair, and loops can be seen extending microns away from axial chromomeres. Unusually, these chromosomes are transcribed, and nascent RNA is attached to both loops and chromomeres (Snow and Callan 1969). Note, however, that these loops only become visible on dispersing chromatin in hypotonic buffers, and none are seen in sections of whole oocytes where chromatin appears as a granular aggregate. Therefore, some transcription units may be stripped off the granules during dispersal, and possible intermediates in such a processsmall granules-can be seen scattered around loops (Mott and Callan 1975; Cook 2001).

Supercoiling provides additional evidence. Supercoils cannot be maintained in linear eukaryotic DNA without looping. However, lysing cells in $>1 \mathrm{M} \mathrm{NaCl}$ releases "nucleoids" containing superhelical DNA (Cook and Brazell 1975; Benyajati and Worcel 1976), and nascent transcripts are associated with attachment points, but not loops (Jackson et al. 1984a). Nucleoids made from all active cells examined (e.g., fibroblasts, erythroblasts, epithelial cells of men, chickens, frogs, insects) contain such supercoils. In contrast, inactive chicken erythrocytes (and human sperm) yield relaxed DNA, with the supercoiling (and so looping) being lost progressively as they develop (Jackson et al. 1984a). But this evidence is also compromised by the unphysiological conditions used. 
Experiments involving nuclease digestion in isotonic buffers are also consistent with looping. Cutting an unlooped fiber should release long fragments that are then shortened, but the expected long fragments are not seen; rather, kinetics fit the release of short fragments from loops (Jackson et al. 1990, 1996; Jackson and Cook 1993). Other in vitro evidence is also supportive; EM reveals that pure repressors like $\mathrm{Gal}, \mathrm{AraC}$, and $\lambda$ bind to distant sites on one molecule of DNA to loop it (reviewed by Ptashne 1986), and an enhancer can only influence a promoter on another plasmid if the two make molecular contact, which implies that when they are on the same chromosome they must also do so (Mueller-Storm et al. 1989). Contact between an enhancer on one chromosome and a target promoter on another also underlies the phenomenon of transvection seen in Drosophila larvae (Wu 1993; Cook 1997).

The application of two new methods - "chromosome conformation capture" (3C; Dekker et al. 2002) and "RNA tagging and recovery of associated proteins" (RNA TRAP; Carter et al. 2002)-provide excellent support for loops tied through two (or more) active transcription units (Cook 2003). Both methods involve careful fixation, before analysis by polymerase chain reaction of which DNA sequences lie next to each other in 3D space (i.e., after ligation in 3C, or purifying complexes in RNA TRAP). The mouse $\beta$-globin locus control region (LCR) lies tens of kilobases away from the $\beta$-globin genes that it regulates. This LCR is transcribed, and both methods show it contacts the $\beta$-globin gene in erythroid nuclei (where the gene is also transcribed). No contacts are found in brain nuclei, where the gene is inactive (Carter et al. 2002; Tolhuis et al. 2002; Palstra et al. 2003). (Competition between two different genes within the locus for the LCR leads to their alternate transcription, with the nearest one initially being transcribed the most; this is consistent with the transcription frequency being determined by LCR:promoter distance [Hanscombe et al. 1991; Dillon et al. 1997].) Similarly, 3C reveals that two distant "barrier" elements (i.e., scs and scs) flanking the Drosophila 87A7 heat-shock locus-which are both transcribed-lie together (Blanton et al. 2003).

Although none of this evidence is derived from the analysis of living cells, taken together it provides good evidence for looping.

\section{Ever-Changing Attachments}

Many models for looping involve stable interactions between a motif like a MAR with some abundant protein bound to the substructure; this molecular tie would persist from one interphase to the next, be highly conserved, and found in all cells in the population. However, genomic sequencing has 
failed to uncover any such motifs, and a simple experiment demonstrates that different ties are found in different cells in the population. Cells are permeabilized in an isotonic buffer, treated with a nuclease like EcoRI, detached fragments removed, and remaining fragments analyzed. If the same DNA ties were found in all cells (Fig. 1a), removing all but $10 \%$ cellular DNA should leave the ties enriched tenfold. However, enrichments are never this high, implying that the same ties are not found in all cells and that they change continually (Fig. 1b; Dickinson et al. 1990; Jackson et al. 1990, 1996; Jackson and Cook 1993).

\section{Constrained Diffusion of DNA Within Loops}

Chromatin dynamics can be monitored in living cells containing lac operator arrays integrated into a chromosome if they also express the repressor tagged with GFP; the repressors bound to the array appear as a moving spot (Robinett et al. 1996; Gasser 2002; Spector 2003). Analyses of the kinetics are consistent with the array diffusing randomly over short distances. In yeast, the array can sample a considerable fraction of nuclear volume in minutes (Heun et al. 2001). In larger fly and human nuclei, the local neighborhood (diameter $\sim 500 \mathrm{~nm}$ ) is sampled roughly as rapidly, but diffusion further a field is constrained-presumably by neighboring chromatin (Marshall et al. 1997; Vazquez et al. 2001; Chubb et al. 2002; Chubb and Bickmore 2003).

\section{Active Transcription Units Are Attached Through Engaged Polymerases}

Which proteins and DNA motifs constitute the molecular ties? In experiments like that illustrated in Fig. 1, the residual fragments prove to be parts of transcription units associated with engaged polymerases. For example, they hybridize with poly $(\mathrm{A})^{+}$RNA (Jackson and Cook 1985) and contain active rDNA cistrons (Dickinson et al. 1990), while cloning and sequencing over 100 randomly selected ones shows they are nearly all parts of transcription units (Jackson et al. 1996). Moreover, they remain associated with engaged polymerases; removing most chromatin in an isotonic buffer does not reduce polymerizing activity, whether it be the total activity or due to polymerases I or II (Jackson and Cook 1985; Dickinson et al. 1990). These polymerases cannot be tethered to the substructure through nascent transcripts as they remain after RNase treatment. (Note that when the experiment illustrated in Fig. 1 is conducted in nonisotonic buffers, different 
fragments [e.g., MARs and SARs] are found to be attached depending on the buffer used [above].)

A detailed study of a model loop confirms that engaged polymerases mediate attachments (Jackson and Cook 1993). When a few plasmids carrying the SV40 origin of replication are transfected into monkey cells (i.e., cos 7), they replicate over 2-3 days to give hundreds of minichromosomes. After permeabilization in an isotonic buffer, nearly all these model loops $(\sim 5 \mathrm{~kb})$ resist electroelution and so must be attached to the substructure. Transfecting in progressively more DNA increases the number of attached plasmids up to a maximum of $\sim 1200$, but then higher inputs generate additional unattached ones. This suggests there are a saturable number of attachment sites. Only the attached population is active, as eluting the unattached fraction does not reduce plasmid-specific transcription. Cutting with HaelII and removing most of the resulting $\sim 400 \mathrm{bp}$ fragments (as in Fig. 1) also has little effect on transcription but it leaves

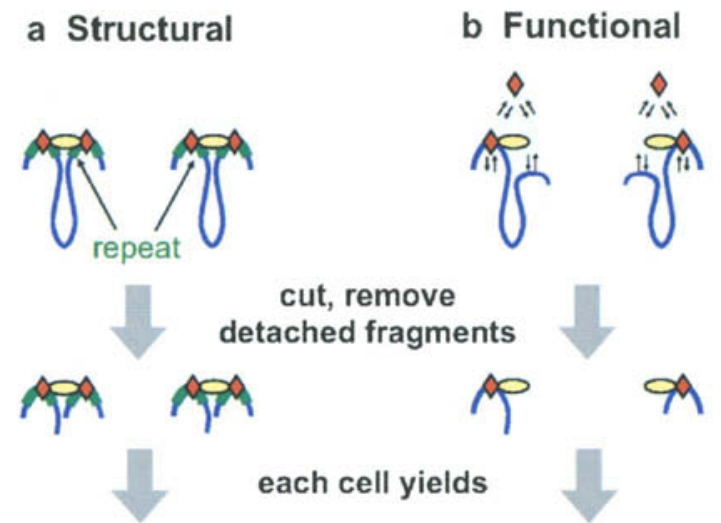

same attached set

different attached set

Fig. 1. Molecular ties. a Static (structural). DNA repeats (green) in two cells bind to the same protein complexes (ovals, diamonds), looping the fiber. After cutting with a nuclease and removing detached fragments, the same set of repeats from each cell remain bound; when $10 \%$ DNA remains, repeats are enriched tenfold. $b$ Dynamic (functional). The fiber is looped by attachment to a protein complex, but both attachments and proteins in the complex change from moment to moment. After cutting and removing detached fragments, a different set of fragments remain attached in the two cells; when $10 \%$ DNA remains, no fragment is enriched tenfold. This result is obtained if cutting and removal are carried out in isotonic buffers; essentially all active transcription complexes also remain attached. Reprinted with permission from Cook 2003. 
fragments from within one or other of the two transcription units. Quantitative analysis shows that each minichromosome is attached at 1-2 points through either one of the two promoters in the plasmid or the body of the transcription units.

Support for the idea that polymerases act as the ties comes from the regeneration of loops from unlooped sperm DNA (Gall and Murphy 1998). When demembranated sperm heads (which are inactive and contain unlooped DNA; above) are injected into the germinal vesicle of amphibian oocytes, the heads swell, accumulate polymerase II, and begin to be transcribed. If the contents of the germinal vesicle are now dispersed in a hypotonic buffer, lampbrush loops derived from both injected sperm and host are seen. The generation of lampbrushes from sperm DNA depends on transcription, as actinomycin D prevents it. Moreover, the active form of polymerase II (marked by hyperphosphorylation of serine 5 in the heptad repeats of the C-terminal domain of its catalytic subunit) becomes concentrated in the lampbrush axis.

Polymerases elongate at $\sim 1.8 \times 10^{3}$ nucleotides/min, and take $\sim 10$ min to transcribe a typical human gene (Kimura et al. 2002). While transcription continues, an active transcription unit will remain attached, and only on termination will it detach to leave the bound polymerase that is now free to exchange with others in the soluble pool.

\section{Other Kinds of Attachment}

Transcription factors bound to their (untranscribed) DNA targets probably mediate additional attachments, as those targets resist nucleolytic detachment from the substructure. The first hint that this was so came from studies on nucleoids derived from rat cells transformed by polyoma virus; when most DNA was detached with EcoRI, fragments containing viral enhancers remained (Cook et al. 1982). These results were confirmed using isotonic buffers; thus, minichromosomes are attached as much through nontranscribed promoters as through the body of transcription units (above). These kinds of attachment are unlikely to persist for long, as most GFP-tagged transcription factors remain bound to DNA only for seconds (Misteli 2001 b; Chen et al. 2002; Hoogstraten et al. 2002). And likely to be established only when assembled into preinitiation complexes, as specific transcription factors like Spl and C/EBP are detached with the body of the loop by HaellI digestion; while in contrast basal factors like TFIIB and TFIIH remain (Kimura et al. 1999). 
Another kind of tie - not to a factory-may be essentially permanent. Histones can carry a "code" (Fischle et al. 2003; Lachner et al. 2003) that ensures they bind tightly to others in heterochromatin or to the lamina (Polioudaki et al. 2001). These are probably the ones that GFP-tagging indicates do not exchange except when DNA is replicated (Kimura et al. 2001), so they can sequester a loop permanently away from a factory. For example, genes involved in immunoglobulin rearrangements are repositioned to centromeric heterochromatin during lymphocyte development coincident with their inactivation (Brown et al. 1999). Other kinds of tie probably exist only fleetingly, and will be best analyzed in vivo (e.g., by fluorescence correlation spectroscopy; Lippincott-Schwartz et al. 2001; Weidemann et al. 2003). These arise because chromatin presents such a huge binding surface to the nucleoplasm; then, many so-called soluble nuclear proteins probably spend much of their time bound transiently to it through low-affinity interactions.

\subsection{Clusters of Active Polymerases Organize Rosettes of Loops}

\section{A Model for Genome Organization}

The principles and results described above lead to a general model for the organization of all genomes (Fig. 2; Cook 1995, 2002). When genes strung along a template are transcribed, active polymerases form into clusters to loop intervening DNA. We call one of these clusters a "factory" as it contains several polymerizing complexes working on different transcription units. Each factory would be surrounded by a rosette (or "cloud") of loops, and strings of nucleosomes and factories (plus surrounding clouds) would constitute the major architectural motifs responsible for organizing the genome. As we have seen, transcription factors in factories would mediate additional attachments. Then, RNA polymerase is not only an enzyme, but a critical structural component that ties the genome in loops. Note that the 3C and RNA TRAP methods provide powerful evidence for the local contact between two active transcription units; for example, the LCR only contacts the $\beta$-globin gene that it regulates when both are transcribed (above). 


\section{Evidence That Active Polymerases Do Not Track}

Textbooks tell us that active RNA polymerases track like locomotives down their templates. In contrast, in our model active polymerases are attached to the substructure, and the immobilized enzyme works by reeling

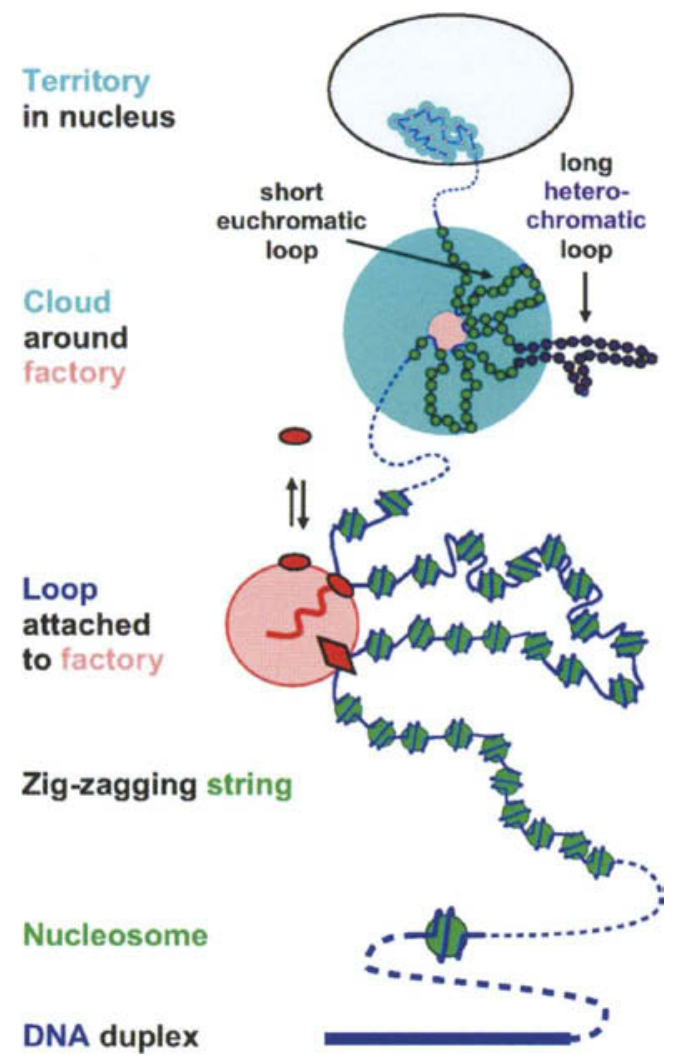

Fig. 2. A model for genome folding. DNA is wound into a nucleosome, and then a zig-zagging string of nucleosomes is tied to a factory through a cluster of transcription factors (diamond) or an active polymerase (oval). Components of the factory exchange with the soluble pool, and attachments to the factory are made and broken as factors dissociate and transcription terminates. Ten to twenty loops (only three are shown) of 5-200 kbp form a cloud around the factory; long, static, loops are likely to become heterochromatic and attached to the lamina. Fifty to one hundred clouds then form a chromosome territory. Reprinted with permission from Cook 2001 and Cook 2003. 
in its template (Cook 1999). Evidence for this is of three general types. First, a tracking polymerase would generate a transcript that is entangled about the template, but this problem does not arise if the polymerase is immobilized. Second, biochemical results indicated that active genes, RNA polymerases, and nascent transcripts are all so closely associated with the underlying structure that they remain when most chromatin is removed with nucleases (as in Fig. 1). Third, we developed a method for localizing nascent transcripts with high resolution, and used it to show that active polymerases engaged on a number of different transcription units are concentrated in a limited number of discrete sites (diameter $\sim 50 \mathrm{~nm}$ ) firmly associated with the substructure. (Engaged polymerases are allowed to extend transcripts by a few nucleotides in Br-UTP or biotin-CTP before the resulting tagged RNA is immunolabeled [Jackson et al. 1993].) As there turn out to be 8 -fold more active molecules of RNA polymerase in a HeLa cell than transcription sites, and as only one polymerase is typically engaged on a transcription unit, each site (diameter $\sim 50 \mathrm{~nm}$ ) must contain $\sim 8$ different polymerases active on $\sim 8$ different units.

This suggests active polymerases are immobilized, but can they then work? There is good evidence they can, as tethering them to a slide or plastic bead has no effect on the rate of polymerization of nucleotide triphosphates (Schafer et al. 1991; Cook and Gove 1992). They can be viewed as motors that haul in their templates. They are powerful ones largely due to their low gearing; for each triphosphate hydrolyzed, DNA is reeled in by $\sim 0.34 \mathrm{~nm}-$ one-tenth and one-hundredth the step-lengths respectively of kinesin and myosin V (Gelles and Landick 1998).

\section{Specialized Factories}

We are all familiar with the prototypic mammalian transcription factorythe nucleolus - which is dedicated to the synthesis of 45S rRNA and the production of ribosomes (Grummt 2003). Active polymerase II and III are also each concentrated in their own discrete factories dedicated to the production of particular transcripts. Thus, in a HeLa nucleus polymerase II transcripts (but not polymerase III, or its transcripts) are concentrated in $\sim 8000$ nucleoplasmic sites, while polymerase III transcripts (but not polymerase II, or its transcripts) are found in another $\sim 2000$ sites (Pombo et al. 1999).

Some factories specialize even further, and become dedicated to the transcription of specific sets of genes. Examples include: OPT domains (transcribing genes depending on Oct1 and PTF; Pombo et al. 1998), sites containing $\beta$-globin and LCR transcripts (above), stress granules (tran- 
scribing satellite repeats; Jolly et al. 2004), CBs (transcribing snRNAs; Callan et al. 1991; Frey et al. 1999; Jacobs et al. 1999), and perinucleolar polymerase III factories (transcribing tRNAs; Thompson et al. 2003).

\section{Factories Contain Many Machines Required to Make Mature Transcripts}

Active RNA polymerase II is part of a huge complex that carries out many-perhaps all -of the functions (RNA synthesis, capping, splicing, polyadenylation) required to generate a mature message (Maniatis and Reed 2002; Proudfoot et al. 2002). This complex probably also proofreads mRNAs before going on to destroy faulty ones along with any peptides generated during proofreading (Iborra et al. 2001, 2004; Andrulis et al. 2002; Brogna et al. 2002; Libri et al. 2002; Lykke-Andersen 2002). Proofreading involves the nonsense-mediated decay (NMD) pathway (Hilleren and Parker 1999); this probably uses ribosomes to scan mRNAs for inappropriately placed (i.e., premature) termination codons (PTCs), and-if detected-triggers the destruction of those faulty messages (along with any misfolded peptides that might result from proofreading). Nascent peptides-which are presumably made during the scanning by the ribosomes-are found in the nucleoplasmic transcription factories, together with components of the translation and NMD machineries. As inhibiting transcription immediately inhibits this nuclear protein synthesis, the processes must be tightly coupled (Iborra et al. 2001). Moreover, the transcriptional, translational, NMD, and degradative machineries colocalize and coimmunoprecipitate; selected components (translational initiation factor eIF4E, ribosomal subunit S6, NMD factors UPF1/2) also copurify with the catalytic subunit of the polymerase, probably by binding to its $\mathrm{C}$-terminal domain (Iborra et al. 2004).

\subsection{Gene Activation}

\section{Local Concentrations of Polymerases and Promoters}

Nuclei of HeLa cells contain a dispersed pool of RNA polymerase II present at $\sim 1 \mu \mathrm{M}$, but this is unlikely to account for much transcription because the local concentration in a factory is $\sim 1000$-fold higher (Cook 2001). This is especially so when promoters are tethered close to a factory. 
Compare two promoters in a loop, where one lies $\sim 4$-fold further away along the DNA from the factory. The distant promoter will be confined to a 64-fold larger volume around the factory (as volume depends on radius ${ }^{3}$ ). This reduces its local concentration by the same amount, and so the frequency with which it contacts the factory. As a result, distant promoters are much less likely to initiate than proximal ones. The long tether has another effect; it buffers the distant promoter from transcription-driven movement, and this immobility makes it likely to acquire the histone code characteristic of "closed" chromatin. The context then becomes selfsustaining: productive collisions of the nearer promoter with the factory attract factors increasing the initiation frequency, and the longer the distant promoter remains inactive the more it is likely to be embedded in heterochromatin.

\section{Gene Regulation and Promoter-Factory Distance}

The probability that a promoter collides productively with a factory is increased by increasing promoter mobility (by "opening" chromatin), increasing promoter-factory affinity (through binding of appropriate factors), and reducing promoter-factory distance (by shortening the tether; Iborra et al. 1996; Cook 2003). It will also depend on which other promoters compete for binding sites in nearby factories. For example, a polymerase II unit might be "silenced" by nearby polymerase II units (because they compete too effectively for a polymerizing site) or polymerase III units (because they attach to a remote polymerase III factory distant from any polymerase II factory). Alternatively, adjacent transcription units can stimulate activity. Consider the activation of the human $\varepsilon$-globin gene during development. We imagine that it is initially embedded deep in heterochromatin far from a factory. During erythroblast development, the concentration of critical activators rises so the LCR-which would be in open chromatin on the edge of the heterochromatin-now has an increased affinity for the factory. Once the LCR attaches and transcription begins, a polymerase reels in the template. This transiently subdivides the long loop into two smaller ones and the associated movement reverses the histone code, to open $\varepsilon$-globin and bring it closer to the factory; now, it is much likelier to attach. Active transcription units can also act as barriers that prevent the spread of heterochromatin down the chromatin fiber; the inevitable movement associated with activity counteracts histone aggregation and the spread of an inactive histone code. Therefore, the pattern of activity of adjacent genes on the chromosome will also determine whether or not a particular gene is active. 


\subsection{Conclusions}

This model illustrated in Fig. 2 has several advantages. First, it is general, and can easily be extended to bacteria. Thus, lysing bacteria in a detergent and $1 \mathrm{M} \mathrm{NaCl}$ releases the prototypic factory-a cluster of still-engaged polymerases surrounded by DNA loops. Transcription maintains this structure, as inhibiting it with rifampicin or treatment with ribonuclease (RNase) unfolds it (Pettijohn 1996). Moreover, GFP-tagging reveals that RNA polymerases are concentrated in discrete foci, each of which probably contains several different operons encoding rRNA (Lewis et al. 2000; Cabrera and Jin 2003). Second, it is a minimalist model in which all the basic structural motifs are defined. Third, we have seen it can readily explain how gene activity is regulated. Fourth, it can be extended to mitosis. Then, the contour length of the loops and the basic shape of the chromatin clouds remain unchanged (Jackson et al. 1990; Manders et al. 1999), and decreased transcription coupled to increased cloud:cloud and factory:factory aggregation could drive reassembly into the most compact and stable structure, a cylinder of nucleosomes around an axial core containing the remnants of the factories (Cook 1995). Despite these advantages, many questions remain. For example, we still know very little about the microarchitecture of factories, or what maintains their structure as their constituents exchange continually with others in the surroundings.

Three different kinds of motion of the chromatin loop have been described: (i) the random Brownian motion of DNA segments within the loop, (ii) the directed transcription-dependent reeling-in by immobilized polymerases that continuously changes the contour length of one particular loop, and (iii) the making/breaking of the molecular ties that attach loops to the factory (so adjacent loops split/merge as polymerase initiate/terminate or transcription factors bind/dissociate). These three motions counteract the tendency of chromatin to condense into heterochromatin, with a consequential alteration in histone code.

\section{Acknowledgments}

We thank our colleagues for helpful discussions, and the Ministry of Education, Culture, Sports, Science and Technology of Japan, the BBSRC, Cancer Research UK, and The Wellcome Trust for support. 


\section{References}

Andrulis ED, Werner J, Nazarian A, Erdjument-Bromage H, Tempst P, Lis JT (2002) The RNA processing exosome is linked to elongating RNA polymerase II in Drosophila. Nature 420:837-841

Becker M, Baumann C, John S, Walker DA, Vigneron M, McNally JG, Hager GL (2002) Dynamic behavior of transcription factors on a natural promoter in living cells. EMBO Rep 3:1188-1194

Belmont AS (2002) Mitotic chromosome scaffold structure: new approaches to an old controversy. Proc Natl Acad Sci USA 99:15855-15857

Benyajati C, Worcel A (1976) Isolation, characterization and structure of the folded interphase genome of Drosophila melanogaster. Cell 9:393-407

Blanton J, Gaszner M, Schedl P (2003) Protein:protein interactions and the pairing of boundary elements in vivo. Genes Dev 17:664-675

Brogna S, Sato TA, Rosbash M (2002) Ribosome components are associated with sites of transcription. Mol Cell 10:93-104

Brown KE, Baxter J, Graf D, Merkenschlager M, Fisher AG (1999) Dynamic Repositioning of genes in the nucleus of lymphocytes preparing for cell division. Mol Cell 3:207-217.

Cabrera JE, Jin DJ (2003) The distribution of RNA polymerase in Escherichia coli is dynamic and sensitive to environmental cues. Mol Microbiol 50:1493-1505

Callan HG, Gall JG, Murphy C (1991) Histone genes are located at the sphere loci of Xenopus lampbrush chromosomes. Chromosoma 101:245-251

Carter D, Chakalova L, Osborne CS, Dai Y-F, Fraser P (2002) Long-range chromatin regulatory interactions in vivo. Nat Genet 32:623-626

Chen D, Hinkley CS, Henry RW, Huang S (2002) TBP dynamics in living human cells: constitutive association of TBP with mitotic chromosomes. Mol Biol Cell 13:276-284

Chubb JR, Bickmore WA (2003) Considering nuclear compartmentalization in the light of nuclear dynamics. Cell 112:403-406

Chubb JR, Boyle S, Perry P, Bickmore WA (2002) Chromatin motion is constrained by association with nuclear compartments in human cells. Curr Biol $12: 439-445$

Cook PR (1988) The nucleoskeleton: artefact, passive framework or active site? J Cell Sci 90:1-6

Cook PR (1995) A chromomeric model for nuclear and chromosome structure. J Cell Sci 108:2927-2935

Cook PR (1997) The transcriptional basis of chromosome pairing. J Cell Sci 110:1033-1040

Cook PR (1999) The organization of replication and transcription. Science 284:1790-1795

Cook PR (2001) Principles of nuclear structure and function. Wiley, New York, pp 86-88, 182-184

Cook PR (2002) Predicting three-dimensional genome structure from transcriptional activity. Nat Genet 32:347-352 
Cook PR (2003) Nongenic transcription, gene regulation and action at a distance. J Cell Sci 1 16:4483-4491

Cook PR, Brazell IA (1975) Supercoils in human DNA. J Cell Sci 19:261-279

Cook PR, Gove F (1992) Transcription by an immobilized RNA polymerase from bacteriophage T7 and the topology of transcription. Nucleic Acids Res 20:3591-3598

Cook PR, Lang J, Hayday A, Lania L, Fried M, Chiswell DJ, Wyke JA (1982) Active viral genes in transformed cells lie close to the nuclear cage. EMBO J $1: 447-452$

Dekker J, Rippe K, Dekker M, Kleckner N (2002) Capturing chromosome conformation. Science 295:1306-1311

Dickinson P, Cook PR, Jackson DA (1990) Active RNA polymerase I is fixed with in the nucleus of HeLa cells. EMBO J 9:2207-2214

Dillon N, Trimborn T, Strouboulis J, Fraser P, Grosveld F (1997) The effect of distance on long-range chromatin interactions. Mol Cell 1:131-139

Dundr M, Hoffmann-Rohrer U, Hu Q, Grummt I, Rothblum LI, Phair RD, Misteli $T$ (2002) A kinetic framework for a mammalian RNA polymerase in vivo. Science 298:1623-1626

Fischle W, Wang Y, Allis CD (2003) Binary switches and modification cassettes in histone biology and beyond. Nature 425:475-479

Frey MR, Bailey AD, Weiner AM, Matera AG (1999) Association of snRNA genes with coiled bodies is mediated by nascent snRNA transcripts. Curr Biol 9:126-135

Gall JG, Murphy C (1998) Assembly of lampbrush chromosomes from sperm chromatin. Mol Biol Cell 9:733-747

Gasser SM (2002) Visualizing chromatin dynamics in interphase nuclei. Science 296:1412-1416

Gelles J, Landick R (1998) RNA polymerase as a molecular motor. Cell 93:13-16

Grummt I (2003) Life on a planet of its own: regulation of RNA polymerase I transcription in the nucleolus. Genes Dev 17:1691-1702

Hanscombe O, Whyatt D, Fraser P, Yannoutsos N, Greaves D, Dillon N, Grosveld F (1991) Importance of globin gene order for correct developmental expression. Genes Dev 5:1387-1394

Heun P, Laroche T, Shimada K, Furrer P, Gasser SM (2001) Chromosome dynamics in the yeast interphase nucleus. Science 294:2181-2186

Hilleren P, Parker R (1999) Mechanisms of mRNA surveillance in eukaryotes. Annu Rev Genet 33:229-260

Hoogstraten D, Nigg AL, Heath H, Mullenders LH, van Driel R, Hoeijmakers JH, Vermeulen W, Houtsmuller AB (2002) Rapid switching of TFIIH between RNA polymerase I and II transcription and DNA repair in vivo. Mol Cell 10:1163-1174

Iborra FJ, Pombo A, McManus J, Jackson DA, Cook PR (1996) The topology of transcription by immobilized polymerases. Exp Cell Res 229:167-173

Iborra FJ, Jackson DA, Cook PR (2001) Coupled transcription and translation within nuclei of mammalian cells. Science 293:1 139-1 142 
Iborra FJ, Escargueil AE, Kwek KY, Akoulitchev A, Cook PR (2004) Molecular cross-talk between the transcription, translation, and nonsense-mediated decay machineries. J Cell Sci 117:899-906

Ivarie RD, Schacter BS, O'Farrell PH (1983) The level of expression of the rat growth hormone gene in liver tumour cells is at least eight orders of magnitude less than that in anterior pituitary cells. Mol Cell Biol 3:1460-1467

Jackson DA (2003) The principles of nuclear structure. Chromosome Res 11:387401

Jackson DA, Cook PR (1985) Transcription occurs at a nucleoskeleton. EMBO J 4:919-925

Jackson DA, Cook PR (1993) Transcriptionally-active minichromosomes are attached transiently in nuclei through transcription units. J Cell Sci 105:11431150

Jackson DA, McCready SJ, Cook PR (1984a) Replication and transcription depend on attachment of DNA to the nuclear cage. J Cell Sci Suppl 1:59-79

Jackson DA, Patel SB, Cook PR (1984b) Attachment of repeated sequences to the nuclear cage. Nucleic Acids Res 12:6709-6726

Jackson DA, Dickinson P, Cook PR (1990) The size of chromatin loops in HeLa cells. EMBO J 9:567-571

Jackson DA, Hassan AB, Errington RJ, Cook PR (1993) Visualization of focal sites of transcription within human nuclei. EMBO J 12:1059-1065

Jackson DA, Bartlett J, Cook PR (1996) Sequences attaching loops of nuclear and mitochondrial DNA to underlying structures in human cells: the role of transcription units. Nucleic Acids Res 24:1212-1219

Jacobs EY, Frey MR, Wu W, Ingledue TC, Gebuhr TC, Gao L, Marzluff WF, Matera AG (1999) Coiled bodies preferentially associate with U4, U11, and U12 small nuclear RNA genes in interphase HeLa cells but not with U6 and U7 genes. Mol Biol Cell 10:1653-1663

Jolly C, Metz A, Govin J, Vigneron M, Turner BM, Khochbin S, Vourc'h C (2004) Stress-induced transcription of satellite III repeats. J Cell Biol 164:2533

Kimura H, Cook PR (2001) Kinetics of core histones in living human cells: little exchange of $\mathrm{H} 3$ and $\mathrm{H} 4$ and some rapid exchange of H2B. J Cell Biol 153:1341-1353

Kimura H, Tao Y, Roeder RG, Cook PR (1999) Quantitation of RNA polymerase II and its transcription factors in an HeLa cell: little soluble holoenzyme but significant amounts of polymerases attached to the nuclear substructure. Mol Cell Biol 19:5383-5392

Kimura H, Sugaya K, Cook PR (2002) The transcription cycle of RNA polymerase II in living cells. J Cell Biol 159:777-782

Lachner M, O'Sullivan RJ, Jenuwein T (2003) An epigenetic road map for histone lysine methylation. J Cell Sci 116:2117-2124

Lewis PJ, Thaker SD, Errington J (2000) Compartmentalization of transcription and translation in Bacillus subtilis. EMBO J 19:710-718

Li G, Sudlow G, Belmont AS (1998) Interphase cell cycle dynamics of a latereplicating, heterochromatic homogeneously staining region: precise choreo- 
graphy of condensation/decondensation and nuclear positioning. J Cell Biol 140:975-989

Libri D, Dower K, Boulay J, Thomsen R, Rosbash M, Jensen TH (2002) Interactions between mRNA export commitment, $3^{\prime}$-end quality control, and nuclear degradation. Mol Cell Biol 22:8254-8266

Lippincott-Schwartz J, Snapp E, Kenworthy A (2001) Studying protein dynamics in living cells. Nat Rev Mol Cell Biol 2:444-456

Lykke-Andersen J (2002) Identification of a human decapping complex associated with hUpf proteins in nonsense-mediated decay. Mol Cell Biol 22:8114-8121

Manders EMM, Kimura H, Cook PR (1999) Direct imaging of DNA in living cells reveals the dynamics of chromosome formation. J Cell Biol 144:813-822

Maniatis T, Reed R (2002) An extensive network of coupling among gene expression machines. Nature 416:499-506

Manuelidis L (1990) A view of interphase chromosomes. Science 250:1533-1540

Marshall WF, Straight A, Marko JF, Swedlow J, Dernburg A, Belmont A, Murray AW, Agard DA, Sedat JW (1997) Interphase chromosomes undergo constrained diffusional motion in living cells. Curr Biol 7:930-939

Misteli T (2001a) The concept of self-organization in cellular architecture. J Cell Biol 155:181-185

Misteli T (2001b) Protein dynamics: implications for nuclear architecture and gene expression. Science 291:843-847

Mott MR, Callan HG (1975) An electron microscope study of the lampbrush chromosomes of the newt Triturus cristatus. J Cell Sci 17:241-261

Mueller-Storm HP, Sogo JM, Schaffner W (1989) An enhancer stimulates transcription in trans when attached to the promoter via a protein bridge. Cell 58:767-777

Palstra RJ, Tolhuis B, Splinter E, Nijmeijer R, Grosveld F, de Laat W (2003) The beta-globin nuclear compartment in development and erythroid differentiation. Nat Genet 35:190-194

Pederson T (2000) Half a century of "the nuclear matrix". Mol Biol Cell 11:799805

Pettijohn DE (1996) The nucleoid. In: Neidhardt FC, Curtiss R, Ingraham JL, Lin ECC, Brooks Low K, Magasanik B, Reznifoff WS, Riley M, Schaechter M, Umbarger HE (eds) Escherichia coli and Salmonella typhimurium: cellular and molecular biology. ASM Press, Washington, pp 158-166

Polioudaki H, Kourmouli N, Drosou V, Bakou A, Theodoropoulos PA, Singh PB, Giannakouros T, Georgatos SD (2001) Histones H3/H4 form a tight complex with the inner nuclear membrane protein LBR and heterochromatin protein 1 . EMBO Rep 2:920-925

Pombo A, Cuello P, Schul W, Yoon J-B, Roeder RG, Cook PR, Murphy S (1998) Regional and temporal specialization in the nucleus: a transcriptionally-active nuclear domain rich in PTF, Octl and PIKA antigens associates with specific chromosomes early in the cell cycle. EMBO J 17:1768-1778 
Pombo A, Jackson DA, Hollinshead M, Wang Z, Roeder RG, Cook PR (1999) Regional specialization in human nuclei: visualization of discrete sites of transcription by RNA polymerase III. EMBO J 18:2241-2253

Proudfoot NJ, Furger A, Dye MJ (2002) Integrating mRNA processing with transcription. Cell 108:501-512

Ptashne M (1986) Gene regulation by proteins acting nearby and at a distance. Nature 322:697-701

Robinett CC, Straight A, Li G, Willhelm C, Sudlow G, Murray A, Belmont AS (1996) In vivo localization of DNA sequences and visualization of large-scale chromatin organization using lac operator/repressor recognition. J Cell Biol 135:1685-1700

Sachs RK, van den Engh G, Trask B, Yokota H, Hearst JE (1995) A randomwalk/giant-loop model for interphase chromosomes. Proc Natl Acad Sci USA 92:2710-2714

Saitoh Y, Laemmli UK (1978) From the chromosomal loops and the scaffold to the classic bands of metaphase chromosomes. Cold Spring Harbor Symp Quant Biol 58:755-765

Schafer DA, Gelles J, Sheetz MP, Landick R (1991) Transcription by single molecules of RNA polymerase observed by light microscopy. Nature 352:444-448

Sedat J, Manuelidis L (1978) A direct approach to the structure of eukaryotic chromosomes. Cold Spring Harbor Symp Quant Biol 42:331-350

Snow MHL, Callan HG (1969) Evidence for a polarized movement of the lateral loops of newt lampbrush chromosomes during oogenesis. J Cell Sci 5:1-25

Spector DL (2003) The dynamics of chromosome organization and gene regulation. Annu Rev Biochem 72:573-608

Stenoien DL, Patel K, Mancini MG, Dutertre M, Smith CL, O'Malley BW, Mancini MA (2001) FRAP reveals that mobility of oestrogen receptor-alpha is ligand- and proteasome-dependent. Nat Cell Biol 3:15-23

Strukov, YG, Wang Y, Belmont AS (2003) Engineered chromosome regions with altered sequence composition demonstrate hierarchical large-scale folding with in metaphase chromosomes. J Cell Biol 162:23-35

Thompson M, Haeusler RA, Good PD, Engelke DR (2003) Nucleolar clustering of dispersed tRNA genes. Science 302:1399-1401

Tolhuis B, Palstra RJ, Splinter E, Grosveld F, de Laat W (2002) Looping and interaction between hypersensitive sites in the active beta-globin locus. Mol Cell 10:1453-1465

Vazquez J, Belmont AS, Sedat JW (2001) Multiple regimes of constrained chromosome motion are regulated in the interphase Drosophila nucleus. Curr Biol $11: 1227-1239$

Weidemann, T, Wachsmuth, M, Knoch, TA, Müller G, Waldeck W, Langowski J (2003) Counting nucleosomes in living cells with a combination of fluorescence correlation spectroscopy and confocal imaging. J Mol Biol 339, 229240. 
Wu C (1993) Transvection, nuclear structure, and chromatin proteins. J Cell Biol $120: 587-590$ 